\title{
Saberes complexos e educação transdisciplinar
}

\section{Complex knowledge and transdisciplinary education}

\author{
Edgard de Assis Carvalho*
}

\section{RESUMO}

Sistemas complexos contemporâneos exigem a regeneração do humanismo e da ética. A educação transdisciplinar é a base dessa ação política e cognitiva na agonia planetária dos dias presentes.

Palavras-chave: Educação; humanismo; complexidade; transdisciplinaridade.

\begin{abstract}
Contemporary complex systems demand the regeneration of the humanism. Transdisciplinary education is the basis of this political ad cognitive action in the planetary agony of present days.
\end{abstract}

Keywords: education; humanism; complexity; transdisciplinarity.

* Edgard de Assis Carvalho, antropólogo, professor titular da PUC de São Paulo. Correio eletrônico: edgardcarvalho@terra.com.br 
Natureza e cultura não constituem dualidades excludentes. São simultaneamente opostas e complementares. Nós, os primatas humanos, também somos assim: naturais porque inscritos numa complexa ordem biológica; culturais porque capazes de produzir, acumular e comunicar estratégias de sobrevivência e adaptação, a curto, médio e longo prazos, onde quer que nos encontremos. Em resumo, e a idéia é de Edgar Morin, somos 100\% natureza e 100\% cultura, seres vivos uniduais, carregamos conosco uma trajetória onto e filogenética milenar e, igualmente, um vasto acervo cultural constituído pela memória coletiva de espécie.

Treinados pela educação familiar e escolar a afastar delírios, sonhos e loucuras de nossa imaginação e recalcá-los em nossa psique, temos que reaprender a conviver e dialogar com eles, escutá-los com atenção redobrada, introjetar em nossas mentes que somos sábios e loucos, unos e múltiplos, duplos, triplos, quádruplos, e que é exatamente esse componente dialógico, instável e incerto, que viabilizará, sem excessos e ressentimentos, processos civilizatórios solidários e procedimentos educativos religados. Nossa condição de sapiens sapiens demens nos permite viver, sobreviver, afrontar e, talvez, superar a insignificância dos mal-estares pós-modernos, comandados pela unidimensionalidade da tecnociência, pela compulsão da conectividade, pela desrazão da política, pela insuficiência dos afetos.

Precisamos de um novo sujeito do conhecimento, que não seja tecnofóbico nem tecnofílico, e muito menos antropofóbico, que reconheça o papel das tecnologias do infinitesimal, mas admita a força propulsora e antecipatória das múltiplas criações do imaginário. Se fosse possível traduzir esse metaponto de vista numa planilha de valores universais, poderíamos assumir a conservação no lugar da destruição, a cooperação no lugar da competição, a partilha no lugar da concentração, a inclusão no lugar da exclusão, a solidariedade no lugar da xenofobia, a sustentabilidade ecológica no lugar do desenvolvimento tecnológico predatório, a paz no lugar da guerra.

Ao promover os quatro pilares da educação para o século XXI em torno de quatro formas de aprendizagem - conhecer, fazer, viver junto e ser -, a UNESCO estava imbuída da idéia de que a humanidade, a Terra-Pátria, não pode ser concebida como um meio excuso de obter lucros e vantagens, mas como um fim a ser construído por todos e para todos. Trata-se de um processo complexo, a ser exercitado não apenas nas escolas, mas na vida em geral. Um amplo programa co-participativo, restaurador do homem genérico saturado de emoções, valores, utopias e um contrato planetário natural e sociocultural, no qual animais e homens, natureza e cultura, real e imaginário não se separem nunca mais.

A hegemonia da fragmentação que rege o dispositivo educacional impede 
que ações movidas por esse pressuposto sejam postas em prática. Empenhada em transmitir conteúdos e formatar profissionais para um mercado rarefeito de trabalho, a escola, seja ela básica, de segundo ou de terceiro grau, não leva em conta o fato de que a refundação do sujeito responsável exigida pela sociedade do conhecimento requer como ponto de partida a religação e circulação dos saberes, cabeças bem-feitas sempre aptas a contextualizar e não cabeças-feitas fissuradas pelos contornos de sua hiperespecialização.

Em qualquer nível em que se exerça, a educação deve empenhar-se em concentrar esforços sintonizados na construção de saberes universalistas que não neguem nenhuma forma de diversidade, na formação de pensadores indisciplinados, capazes de enfrentar os desafios do conhecimento e criar novas formas de entendimento do mundo a serem vialibilizadas e planejadas para a incerteza dos tempos futuros.

A dupla função da educação consiste em acoplar necessidades básicas de formações e competências, com atitudes metaprofissionais sintonizadas com a natureza, a cultura, o cosmo. Se, em sua quase totalidade, as formas da gestão educacional favorecem a replicação de um modelo pedagógico fechado e endogâmico, qualquer esforço de reforma pressupõe a transdisciplinaridade como horizonte necessário e a transversalidade de métodos, conceitos e teorias como foco primordial.

As inquietações expostas por Karl Marx em sua terceira tese sobre Feuerbach revelam-se mais que atuais nesses tempos de modernidade líquida, essa feliz expressão de Zygmunt Bauman (2001), que sinaliza a fluidez dos tempos e espaços, dos indivíduos, dos amores e da vida em geral. Se concordarmos com a assertiva marxiana de que qualquer teoria da mudança das circunstâncias sóciohistóricas e da educação requer, antes de mais nada, a educação dos educadores, é preciso agir rápido antes que seja tarde demais. Como fazer isso? Fomentando a identidade entre ciências e artes, ciências e tradições, razão e sensibilidades, artes e espiritualidades, cultura científica e cultura das humanidades. Esse deve ser o protocolo intencional mínimo de qualquer governo, partido, das instituições de ensino e pesquisa e, claro, da sociedade civil em seu conjunto.

A substituição da compulsão por critérios disciplinares e quantitativos de avaliação pela pulsão por saberes transdisciplinares é um bom caminho para estimular novas conexões entre professores e alunos, supervisores e diretores, escolas do primeiro e segundo graus, faculdades, universidades, centros de pesquisa. A educação dos educadores tem de reconhecer, e assumir, que a função escolar, em qualquer nível em que se exerça, deve buscar estabelecer e refundar conexões e interconexões complexas entre presente, passado e futuro, tendo como base o trinômio indivíduo, sociedade, espécie.

A transdisciplinaridade não é método, mas estratégia, caminho errático 
que atravessa os saberes. Não se trata de um receituário de procedimentos a serem operacionalizados diante de objetos inertes. A palavra assusta, porque mexe com certezas consolidadas e nichos de poder. Na verdade, trata-se de um domínio cognitivo que se localiza além das disciplinas, uma atitude teóricoconceitual-metodológica assemelhada a uma viagem sem porto definido. Exige conhecimento sedimentado das áreas-tronco do pesquisador, mas vai além delas, para atingir a complexidade de problemas sócio-históricos.

Mesmo que seja reconhecida sua prática na ecologia, na cosmologia, nas ciências da terra e da cognição, a transdisciplinaridade não sepulta a figura do especialista, o que seria algo insensato, mas aposta na formação de educadores sistêmicos, polivalentes, abertos, mestiços, arlequinados, reflexivos, críticos, exílicos, amorosos, utópicos. Talvez esse venha a ser o perfil do intelectual do século 21: um outsider que ultrapassa as fronteiras de seu saber específico para empenhar-se no diagnóstico da incerteza do mundo. Por isso, os cruzamentos transdisciplinares não propõem um sincretismo entre ciência e religião, ciência e arte, ciência e mito, mas um diálogo permanente entre esses circuitos dos saberes.

O que se busca são metapontos de vista a partir dos quais se possa entender a interação dos domínios multidimensionais da vida. Se sua base é biológica e sócio-histórica, não é mais possível isolar o natural do cultural, mas sim ir além deles. $\mathrm{O}$ formato dos saberes transdisciplinares é nutrido pelas polifonias da arte, da poesia, da filosofia, da ciência, da tradição, sem que se estabeleça nenhuma diferença de natureza ou grau entre elas. Graças a estudos transhistóricos e transreligiosos e ao surgimento de conceitos novos como os de transnacionalidade e transpolítica, delineiam-se condições epistemológicas capazes de inaugurar uma ecologia profunda conduzida pela razão aberta e retroalimentada por dialogias, recursividades e hologramas.

Os sete saberes necessários à educação do futuro (MORIN, 2000) propostos por Edgar Morin para a reforma do ensino médio francês, em 1997, nos estertores do governo socialista de François Mitterand, mesmo que não tenham sido implementados, constituem importante fonte de inspiração, um bom começo para se repensar a educação no Brasil, se aplicados e problematizados em todas as áreas do pensamento e em todos os níveis do ensino privado, público ou comunitário.

As cegueiras do conhecimento, a objetividade das certezas, as intermitências da condição humana, os percalços da identidade terrena, o caráter provisório da ciência, os obstáculos à compreensão, as intolerâncias interculturais, as utopias da antropoética e da comunidade de destino devem ser cotidianamente problematizados, dadas as contradições da idade de ferro planetária em que vivemos. São saberes mais do que necessários e urgentes. Claro que não devem 
ser entendidos como disciplinas, programas ou seqüências de pré-requisitos curriculares. São, isso sim, um conjunto de operadores cognitivos a serem postos em marcha por pensadores plurais empenhados em repensar o papel da educação.

Se for preciso que o princípio da incerteza racional contamine a todos, que isso seja feito e assumido sem maiores delongas. A sociedade tem que desobedecer o paradigma do ocidente, disjuntor do sujeito e do objeto, para que o pensamento selvagem, imaginal, próximo da intuição sensível, assuma seu devido lugar. Não se trata de denegar a força da razão, mas introjetar que a via racional não é a única forma de acessar o real por meio de teorias, conceitos, proposições. O imaginário contido nos mitos, na literatura, na música, no cinema são exemplos disso. Se real-imaginário é totalidade indivisível, precisamos aprender a religar a parte e o todo, o texto e contexto, o global e local, o universal e o planetário, para que os paradoxos gerados pelo globalismo tecnoeconômico não sejam assumidos como redutos de certeza. Passar a entendê-los como incompletos, inconsistentes e indecidíveis é um começo para a almejada "mudança de paradigma".

Assumir que a educação do futuro deve conter como preceito inegociável a ética da compreensão planetária implica entendê-la não como um conjunto de proposições abstratas, ou como uma planilha de regras formais outorgada pelos donos do poder, mas como atitude deliberada de todos aqueles que acreditam que a cultura de paz, a construção de solidariedades nacionais e transnacionais, a consolidação das democracias, a efetiva colaboração entre todas as culturas da Terra não é algo intangível.

A religação dos saberes que serve de ponto de partida para a realização desses metapontos de vista não se situa apenas no plano das idéias e das utopias não realizáveis. É teoria e prática, ação política e prática ética, reflexão criativa e impulsão pelo saber. A palavra religação define com propriedade a intenção de superação das dicotomais cartesianas. Ela não acaba com as disciplinas, sejam elas quais forem. Seria descabido e insensato não reconhecer os progressos dos conhecimentos na contemporaneidade. A religação requer, porém, um choque cultural que invista contra as estruturas da repetição - tecnoburocracia escolar, programas superados, estratégias de dominação, bibliografias ultrapassadas - e aposte nas estruturas da criatividade - os desregramentos das artes, a polifonia da literatura, a estética dos mitos, as incertezas das teorias e modelos.

A repetição é apaziguadora; é, igualmente, esquizofrênica, pois cria um sujeito cindido consigo mesmo. Na sala de aula é uma coisa, na atividade cidadã outra. O sujeito é sempre endo e exo-referente, duplo, razão e loucura. Intelectuais costumam separar a vida do sujeito cognoscente, geralmete ocultada, das idéias que professa. Esquecem-se de que tudo aquilo que dizemos é produzido 
por uma história pessoal, por vezes cheia de sofrimentos, dores, percalços e algumas poucas alegrias. A restauração do sujeito responsável na educação requer a explicitação da dialogia vida-idéias. Claro que a convivência entre ambas nunca é plenamente pacífica. É, porém, do embate entre elas que um novo sujeito do conhecimento poderá emergir. "Toda vez que a ciência progrediu no mundo, pelo menos a partir do século dezessete, a criatividade explodiu sem controle. Foi assim com Darwin, Freud, Marx e tantos outros pensadores que instauraram a criatividade e não ficaram refestelados no conforto da repetição" (CARVALHO, 2008).

Com vontade política, desapego individualista, abertura cognitiva e consciência espiritual não é impensável admitir que a educação sustentável, ou a ecoalfabetização se preferirmos, é a única saída para nosso futuro. É preciso ir além das leis de equilíbrio e da fábrica da ordem da cultura, assim como das regulações que os paradigmas do mercado e da informação tentam impor a todos.

Seria ideal assumir que o futuro será sempre indeterminado, composto por uma infinidade de fluxos, brechas, desordens, pontos de fuga, e que, por isso mesmo, a emergência de uma nova aliança entre mundo físico, mundo biológico e mundo cultural constitui o pressuposto irreversível, crucial, inadiável, a ser posto em marcha por uma educação que se paute pela sustentabilidade dos ecossistemas da Terra, pela co-dependência entre todos os seres vivos, plantas, animais, homens.

Para que esse amplo objetivo transdisciplinar seja ultimado, a ética deve ser assumida como valor universal. Essa universalidade não constitui, porém, um catálogo de regras abstratas elaboradas por comitês, comissões ministeriais, conselhos sociais. Trata-se, isso sim, de uma vivência relacional cotidiana a ser elaborada a duras penas diante da crueldade do mundo e do mal-estar civilizatório.

Constante em todas as épocas e lugares, a ética e os atos que a sustentam constituem o alvo máximo de todos os humanos. O que significa ser ético? É possível legislar sobre o que é e o que não é ético, se o ethos, a casa comum, vem sendo degradada e vilipendiada a cada dia que passa? É forçoso reconhecer que estamos enredados num jogo cósmico, um sistema de forças composto por um quadrimotor: a religação, a separação, a integração e a desintegração. Constituído por um embate entre o global e o local, o universal e o particular, cabe ao sistema-mundo decidir se religação e integração prevalecerão sobre os demais. No primeiro caso, pode-se prever a consolidação de uma biopolítica da civilização terrena; no segundo, a expansão descomedida da barbárie.

Se, de acordo com o preceito kantiano, não se deve fazer aos outros aquilo que não se quer que seja feito para nós mesmos, a ética envolve sempre 
um ato de religação com o sujeito, a comunidade, a história, a humanidade, o cosmo e o conjunto dos saberes. Como ato humano que é, a ética mergulha na incerteza do mundo. Se os humanos vivem de acertos e erros, sucessos e insucessos, avanços e retrocessos, os julgamentos éticos - e na educação eles são prioritários - devem sempre ser colocados entre parêntesis, assim como a objetividade, a sexualidade, a racionalidade e as racionalizações. Felicidade, risco, precaução, solidariedade, obediência e revolta devem pesar em qualquer ecologia da ação voltada para atos éticos.

À guisa de exemplo, vejamos o caso da felicidade. Ela não começa com a filosofia, pois a preocupação em ser feliz existiu muito antes que a reflexão filosófica se instalasse sobre a face da Terra. Se o reino dos céus permanece o local imaginário no qual a felicidade pode verdadeiramente ser usufruída, resta saber o que fazer aqui para garantir a existência de um paraíso interior em cada um de nós. É claro que as revoluções científicas dos séculos dezessete e dezoito possibilitaram uma reviravolta na totalidade dos modos de ser e instalaram a hegemonia da razão e os desatinos das racionalizações. O afastamento do caminho do viver-bem abriu caminho para um mundo poroso em que se repete, mais do que se cria. $\mathrm{O}$ mundo da imaginação poética cedeu lugar à realidade da vida prosaica e às promessas prometéicas das tecnociências.

Camuflada por liberdades outorgadas, igualdades cínicas e fraternidades escusas, essa sociedade do controle e da desigualdade espraiou-se para os reinos da política e da cultura. Pequenas felicidades aliadas a duvidosas éticas privacionistas passaram a compensar a imensa dependência econômica, social, política que se instalou no mapa-múndi a partir do esclarecimento das Luzes, da escuridão das guerras, da perda das grandes narrativas.

O tema da ética envolve sempre três movimentos alicerçados na tríade indivíduo-sociedade-espécie: auto-ética voltada para a meditação das ações e sentimentos que vivenciamos a todo o momento, sejam elas o lazer, a alegria, o amor, o sofrimento, a dor, o companheirismo, a amizade; sócio-ética dirigida para relações que travamos com os outros, no sentido de garantir um quantum de solidariedade que viabilize as agruras globalizadas com as quais nos defrontamos a toda hora; antropoética fundada na identidade humana comum, na preservação e na sustentabilidade de nossa terra-pátria, algo que, simplesmente, garanta para as futuras gerações o direito de existir.

Não há palavras de ordem, apenas caminhos, horizontes, proposições, precauções, formatos que vislumbram o papel da ética na cultura, na educação e, claro, na pesquisa praticada em instituições e órgãos estatais de amparo à pesquisa e nas políticas ministeriais. Refletir sobre eles, repensar o papel que desempenhamos na formação de gerações responsáveis pelos destinos planetários é tarefa urgente. A ética não se reduz a um conjunto normativo e nem a 
uma mera ação comunicacional. Constitui, isso sim, um fundamento ontológico que impede qualquer ser humano de praticar intencionalmente o mal, que o força a exercitar o diálogo intercultural e fazer o bem, dentro da sala de aula e fora dela.

Com isso, é possível pensar numa nova hominescência, uma emergência hominiana como denominou Michel Serres (2003). Trata-se de um neologismo criado pelo autor, uma provocação, um grito de alerta que coloca a todos sob a égide do princípio da responsabilidade intercultural. Em primeiro lugar, é forçoso reconhecer que as biotecnologias mudam nossas relações com a vida, assim como bombas atômicas, guerras e genocídios alteram nossas relações com a morte. Nunca dispusemos de tantos meios para melhorar o mundo e, mesmo assim, não o fazemos. Nossos poderes mudaram de escala.

Onipotentes e inconscientes de nossa fragilidade, devastamos os ecossistemas de tal maneira que, nessa primeira década do século 21 , vivemos sem garantias de um futuro sustentável. Esse é o sentido da hominescência: uma esperança que se mescla com inquietudes generalizadas e medos recalcados. Permanece o hiato, afirma Serres, entre o Homo Terminator, voltado para as destruições e o Homo Universalis, responsável por si mesmo e pelo mundo. Será possível que um deles prevaleça sobre o outro?

Ao separar corpo e mente, a ciência reduziu o primeiro a experiências de treinamento e repetição, e o segundo a circuitos neuronais especializados. Empenhados em religá-los, os novos educadores terão de assumir o fato de que o segredo da vida permanece em aberto, e isso porque a hominização se processa sempre por meio de desvios, equilíbrios, desordens e bifurcações que envolvem múltiplas ações e retroações entre a mente e a natureza, o contingente e o necessário, o autônomo e o heterônomo. Esses saberes constituem circuitos de hominescência, ciclos culturais a serem operacionalizados nas instituições escolares, preparando-as para o advento de uma sociedade-mundo solidária, regeneradora da dignidade humana no planeta, nossa habitação comum.

Reassumir esse programa de ação cultural coletiva implica reassumir a universalidade da cultura. Não, a cultura não termina nas fronteiras da tribo, da cidade, da nação. É algo mais amplo, constituído por um mosaico de múltiplas cenografias. Nele se articulam espaços topológicos e projetivos, tempos curtos e longos, micro-espaços e macro-espaços, planos reversíveis e irreversíveis.

A imagem da marchetaria formulada por Serres é adequada para designar o formato desse pressuposto. É ela que dá consistência e expressividade à grande narrativa. É nossa pequena família mundial que, em meio a guerras, violências e extermínios e desigualdades se incumbe de tecê-la. A reconstrução do sujeito, os jogos de linguagem, a boa utopia de um futuro responsável são os alicerces de uma mutação incandescente para todos os seres vivos. Reservatório de matérias, 
conservatório de imagens, nossa Terra requer um homem afinado com valores universais e éticas gerais.

Imbuído desse ideário, Serres (2005) chegou a solicitar às universidades que reformassem seu ensino em prol de um saber comum. Em sua formulação, havia um pressuposto geral dividido em dois macroblocos: o primeiro é empenhado na construção de uma configuração cartográfica branca formada pelas ditas ciências duras que já atingem a universalidade. Trata-se de um registro complexo da evolução da cronopedia. O segundo é constituído pelo mosaico das formas e cores das diversidades culturais. A assimilação dessas diferenças deve ser assumida e tratada pelas pedagogias.

Assumido o pressuposto, passa-se ao programa comum para o primeiro ano das universidades. Ele se subdivide em três grandes plataformas: a primeira, que é incumbida de explicitar o programa comum da especialidade escolhida pelo alunado no ingresso universitário; a segunda, de caráter propedêutico, intitulada A grande narrativa unitária de todas as ciências, composta por quatro unidades: elementos de física e astrofísica, elementos de geofísica, química e biologia, elementos de antropologia geral, elementos de agronomia, medicina e explicitação das múltiplas passagens da natureza à cultura e das relações dos homens com a Terra, a vida e a humanidade. Finalmente, a terceira plataforma, intitulada $O$ mosaico das culturas humanas, é portadora de caráter mais epistêmico. Envolve cinco unidades: elementos de lingüística geral, evolução das linguagens da comunicação, elementos da história das religiões, elementos de ciências políticas e, finalmente, a análise de obras-primas das artes e das sabedorias milenares e a construção do conceito de patrimônios da humanidade.

Se a educação do futuro vier a ser contaminada por esse tipo de "ideologia", os saberes culturais transdisciplinares constituirão uma reserva cultural comum e universal, um patrimônio histórico a ser acessado e preservado por todos os sapiens-demens da Terra. Pensar os saberes no século 21 implica enfrentar as crises da escola e suas possíveis superações, assim como recriar novas humanidades e, antes de mais nada, aprender de outro modo. Incrível constatar, por exemplo, que o fenômeno do iletrismo se espalha por toda parte, como atestam dados empíricos sistematizados em recentes pesquisas.

Ignorâncias ortográficas, vernaculares, gramaticais e sintáticas se ampliam a cada dia. $\mathrm{O}$ fenômeno dos revisores de textos é exemplo disso. Muitas vezes um trabalho é refeito várias vezes sem que adquira a clareza da exposição exigida em qualquer tipo de narrativa. Não se trata de um desentendimento entre autor e revisor, mas ausência de cognição acumulada de ambas as partes. Sítios da internet como o zemoleza.com.br constituem um acinte para a educação. Anúncios que oferecem trabalhos de conclusão de cursos de graduação, de mestrados e doutorados se espalham pelos corredores de escolas e universidades. 
Compilação, inserção, cortes, reaproveitamentos de textos alheios, comumente anônimos, minam a criatividade em todos os níveis do ensino e instalam a impunidade nas avaliações tecnoburocráticas tão a gosto dos sistemas de informação e coleta de dados exigidos pelos aparelhos ideológicos do Estado. À vigilância cognitiva imposta pela fragmentação soma-se a violência cognitiva de saberes cuja autoria é sempre posta em dúvida.

A internet não é culpada disso e nem pode ser julgada como bode expiatório dessa cretinização do conhecimento. Constitui importante fonte de acesso à cultura global, desde que seja entendida como meio e não como fim. Midiaesferas, blogosferas, videoesferas e tantas outras que venham a ser criadas são expressões fenomênicas da globalização da cultura. Em si mesmas, a quantidade de informações que veiculam são ilusórias, não se convertem em mutações paradigmáticas capazes de gerar ou comandar revoluções científicas. $\mathrm{O}$ que fazem é castrar a curiosidade e a inventividade. Acabam por consolidar o velho paradigma natureza-cultura, razão-paixão, oriente-ocidente, impedem $\mathrm{o}$ acesso à grande narrativa.

A formação da cidadania planetária exige especialistas policompetentes, mas também cidadãos imbuídos da necessidade de reformar a cultura. Saberes complexos transversais que sempre envolvem a espiritualidade, a sistêmica e a sinergia são regeneradores da condição humana. O formato dessa política é horizonte inacabado, um projeto e um processo de reticulação em redes não hierárquicas nas quais o trinômio controle-poder-saber poderá ser revertido. Como toda reinvenção que se processa na noosfera, necessita de uma revolução noética, ou seja, novas linguagens, proposições, políticas e, claro, organizações democráticas que sustentem o diálogo intercultural. "Outrora semelhante a um grão denso ou um pequeno cascalho escuro, únicos e duros, o eu agora torna-se múltiplo, transversal, rutilado, assemelhado a um mosaico" (SERRES, 2003, p. 294). Talvez, por isso, quando perguntaram a Einstein o que era a educação, ele respondeu que a verdadeira educação é tudo aquilo que se aprende quando se sai da escola. 


\section{REFERÊNCIAS}

BAUMAN, Z. Modernidade líquida. Tradução: Plínio Dentzien. Rio de Janeiro: Jorge Zahar Editores, 2001.

CARVALHO, E. A. É preciso religar os saberes. Escola particular, ano 11, n. 118, p.13, janeiro 2008. Entrevista.

MORIN, E. Os sete saberes necessários à educação do futuro. Tradução: Catarina Eleonora F. da Silva e Jeanne Sawaya; revisão técnica: Edgard de Assis Carvalho. São Paulo: Cortez; Brasília, DF: UNESCO, 2000.

SERRES, M. Hominescências. O começo de uma outra humanidade? Tradução: Edgard de Assis Carvalho, Mariza Perassi Bosco. Rio de Janeiro: Bertrand Brasil, 2003.

SERRES. M. O incandescente. Tradução: Edgard de Assis Carvalho, Mariza Perassi Bosco. Rio de Janeiro: Bertrand Brasil, 2005.

Texto recebido em 04 de maio de 2008. Texto aprovado em 30 de junho de 2008. 